\title{
PRÁTICAS INTEGRATIVAS E COMPLEMENTARES DE SAÚDE EM UBERLÂNDIA, MINAS GERAIS: O PROCESSO DE IMPLANTAÇÃO NA PERSPECTIVA DOS TRABALHADORES
}

\section{INTEGRATIVE AND COMPLEMENTARY HEALTH PRACTICES IN UBERLÂNDIA, MINAS GERAIS: THE PROCESS OF IMPLEMENTATION IN WORKERS' PERSPECTIVE}

\author{
Cáritas Batista Martins Alves \\ Mestre em Saúde Ambiental e Saúde do Trabalhador - Universidade Federal de Uberlândia (PPGAT) \\ caritasbmalves@hotmail.com
}

Rosimár Alves Querino

Professora Associada do Departamento de Saúde Coletiva do Instituto de Ciências da Saúde da Universidade Federal de Triângulo Mineiro (UFTM) e docente do Programa de Mestrado Profissional em Saúde Ambiental e Saúde do Trabalhador - Universidade Federal de Uberlândia (PPGAT)

rosimar.querino@uftm.edu.br

\begin{abstract}
RESUMO
A Política Nacional de Práticas Integrativas e Complementares (PNPIC), desde 2006 incorpora as Medicinas Tradicionais e Complementares no Sistema Único de Saúde (SUS) e fomenta a inserção dessas terapias pelos municípios. O presente artigo objetiva compreender a implantação das práticas integrativas no município de Uberlândia, Minas Gerais na perspectiva dos trabalhadores que atuaram no processo de criação do Centro de Referência em Práticas Integrativas e Complementares em Saúde (CRPICS). Trata-se de estudo qualitativo desenvolvido com entrevistas semiestruturadas com trabalhadores e gestores. As entrevistas foram analisadas de modo temático. O estudo evidenciou comprometimento dos trabalhadores, envolvimento do conselho de saúde e participação da sociedade civil na institucionalização das Práticas Integrativas e Complementares de Saúde (PICS). Destacou-se a contribuição de financiamento federal no processo de implantação do CRPICS. Dentre os obstáculos enfrentados destacaram-se: resistências oriundas do modelo biomédico, dificuldades para institucionalização das PICS na política e na gestão municipal, reduzido número de trabalhadores para a atuação com PICS e implementação da fitoterapia. A ampliação das PICS na atenção primária e a formação de trabalhadores são fundamentais para a consolidação da PNPIC em âmbito municipal.
\end{abstract}

Palavras Chave: Medicina Integrativa. Terapias Complementares. Políticas Públicas de Saúde.

\begin{abstract}
The National Policy on Integrative and Complementary Practices (PNPIC), since 2006, incorporates the Traditional and Complementary Medicine into the Unified Health System (SUS) and encourages the inclusion of these therapies by the municipalities. This article aims to understand the implementation of integrative practices in the city of Uberlândia, Minas Gerais in the perspective of workers who deal with the process of creating the Reference Center on Integrative and Complementary Practices in Health (CRPICS). It is a qualitative study developed with semi-structured interviews with workers and managers. The interviews were thematically analyzed. The study showed the workers commitment, the health council involvement and participation of the civil society in the institutionalization of integrative and complementary health practices (PICS). The federal funding contribution was highlighted in the implementation process of the CRPICS. Among the obstacles faced were: resistance from the biomedical model, difficulties to institutionalize PICS in politics and municipal management, reduced number of workers in the PICS and phytotherapy implementation. The expansion of PICS in primary care and the training of workers are essential for the consolidation of PNPIC at the municipal level.
\end{abstract}

Keywords: Integrative Medicine. Complementary Therapies. Public Health Policies.

Recebido em: 05/02/2019

Aceito para publicação em: 23/10/2019 


\section{INTRODUÇÃO}

O desenvolvimento de políticas públicas e a regulamentação de outras formas de atenção à saúde com a incorporação das chamadas medicinas populares ou tradicionais nos sistemas nacionais de saúde foram preconizados pela Organização Mundial de Saúde (OMS) na conferência de Alma-Ata, em 1978 (BRASIL, 2015; LUZ, 2005).

Neste período, prevalecia no Brasil a hegemonia da previdência social sobre a saúde pública, o que limitava a assistência médica aos trabalhadores inseridos no mercado formal de trabalho em decorrência do modelo médico-previdenciário. Os centros de saúde se limitavam a oferecer alguns programas e quem não se enquadrava recorreria à filantropia ou ao mercado (L'ABATTE, 2003; SOUZA; BOTAZZO, 2013).

O modelo médico-previdenciário de caráter individualista, médico-centrado e hospitalocêntrico começou a ser questionado com o Movimento da Reforma Sanitária. Este processo teve como marco instituinte a $8^{\text {a }}$ Conferência Nacional de Saúde, realizada em 1986. As propostas dessa conferência foram consagradas com a Constituição Federal de 1988 e com a criação do Sistema Único de Saúde (SUS) (SOUZA; BOTAZZO, 2013).

A adoção de um conceito ampliado de saúde, que inclui condições de alimentação, moradia, educação, transporte, emprego e as formas de organização social de produção, confronta o sistema biomédico vigente, centrado na doença e com foco no indivíduo indiferenciado (PETTRES; DA ROS, 2018). A biomedicina se pauta em intervenções fragmentadas, na medicalização com ênfase na atenção hospitalar com uso intensivo do aparato tecnológico e se distancia dos aspectos culturais e éticos implicados nas escolhas e vivências dos sujeitos e na determinação social da saúde. No contexto de criação do SUS, esse sistema hegemônico, que norteia a formação profissional, a organização dos serviços e a produção de conhecimentos em saúde, é duramente criticado e são reconhecidos seus limites na atenção à saúde das pessoas (FERTONANI et al., 2015).

A legitimação e a institucionalização de novas racionalidades médicas começam a ocorrer paulatinamente, principalmente após a criação do SUS, com a introdução no sistema de saúde de práticas como a homeopatia, a acupuntura e a fitoterapia (BRASIL, 2015).

A criação da Política Nacional de Práticas Integrativas e Complementares (PNPIC) envolveu justificativas de natureza política, técnica, econômica, social e cultural. A PNPIC atendeu à necessidade de se apoiar e incorporar experiências que já vinham sendo desenvolvidas na rede pública e representa mais um passo no processo de implantação do SUS, por ser um modelo de atenção à saúde humanizada e centrado na integralidade do indivíduo com atuações nos campos da promoção, manutenção e recuperação da saúde (ISCHKANIAN; PELICIONI, 2012; BRASIL, 2015).

Para a elaboração da PNPIC foi empreendida uma análise da situação dessas práticas no SUS e ocorreram inúmeras reuniões técnicas e fóruns de estudos com a participação da sociedade e a avaliação do Conselho Nacional de Saúde (CNS). O documento final foi publicado na forma das portarias ministeriais ํㅡ 971, de 3 de maio de 2006, e ํㅜ 1.600, de 17 de julho de 2006 (BRASIL, 2015).

Procurando atender as diretrizes da OMS, nos anos de 2017 e 2018, o Brasil incluiu novas práticas na política, totalizando 29 PICS no SUS (BRASIL, 2018). Contudo, incorporá-las aos serviços ainda é um desafio para os gestores públicos (SANTOS; TESSER, 2012).

Decorridos doze anos da criação da PNPIC, há avanços na implantação dessas práticas no país, mas são escassos os estudos que sistematizam as experiências (OTANI; BARROS, 2011; SANTOS et al., 2011; SILVA, 2012; SOUSA et al., 2012; BILHARINHO JÚNIOR, 2013; TELESI JUNIOR, 2016). Diante da importância de conhecer o modo como essas terapias tem sido ofertadas no SUS, o presente artigo objetiva compreender o processo de implantação das práticas integrativas no município de Uberlândia, Minas Gerais na perspectiva dos trabalhadores que protagonizaram a criação da política municipal e do Centro de Práticas Integrativas.

A implantação da PNPIC no Brasil ainda sofre muitas resistências, sendo poucas as cidades que avançaram em sua efetivação. Vários profissionais que trabalham no Centro de Referência estiveram presentes, acompanharam e lutaram pelo processo de implantação das PICS em Uberlândia. O resgate desse processo histórico na perspectiva dos trabalhadores e visa contribuir para a reflexão sobre os desafios postos à sedimentação desse novo modelo de assistência à saúde e na ampliação de estudos nesta seara. 


\section{METODOLOGIA}

Neste estudo analisa-se o processo de implantação do Programa Municipal de Práticas integrativas e Complementares de Saúde (PMPICS) e o Centro Referência de Práticas Integrativas e Complementares (CRPICS) em Uberlândia, localizado no Triângulo Mineiro. Trata-se de estudo qualitativo e exploratório (MINAYO, 2010).

Uberlândia é o segundo município mais populoso do estado de Minas Gerais, na Região Sudeste do Brasil. Segundo estimativas do Instituto Brasileiro de Geografia e Estatística (IBGE), possuía 676613 habitantes (2017), sendo o mais populoso da região do Triângulo Mineiro.

O processo de construção de dados foi conduzido com entrevistas semiestruturadas que permitiram o registro do modo como cada participante vivenciou tal processo e como identificou os desafios postos à implantação das PICS no sistema de saúde municipal (MINAYO, 2010). Tratou-se de reconstrução do processo histórico com base na história oral (AMADO; FERREIRA, 2006).

Participaram do estudo treze pessoas que atuaram no processo de implantação do PMPICS e do CRPIC: nove servidores municipais; o primeiro coordenador do núcleo de práticas integrativas; a coordenadora da atenção primária à época; um biomédico que participou da equipe do núcleo de práticas integrativas e a atual coordenadora do Centro.

As entrevistas seguiram um roteiro com perguntas relativas à caracterização dos participantes (formação, tempo de atuação no serviço público e inserção nas instituições de saúde municipais), à participação no processo de implantação das PICS, dificuldades encontradas e aceitação das PICS pela população e pelos profissionais. A entrevista semiestruturada permitiu ao entrevistado falar livremente sobre os temas propostos e, também, discorrer sobre aspectos não previstos preliminarmente. Essa técnica possibilitou rica abrangência do tema, valorizando as experiências dos participantes na descrição do processo de implantação das PICS em Uberlândia.

As entrevistas foram áudio-gravadas, transcritas na íntegra e analisadas de modo temático segundo as diretrizes propostas por Braun e Clarke (2006). A análise temática consiste em identificar e analisar os temas presentes no conjunto de dados, a partir dos quais serão constituídas as categorias temáticas (BRAUN; CLARKE, 2006). A análise resultou em três categorias temáticas: Experiências embrionárias na comunidade; O processo de implantação das PICs: luta pela institucionalização; O Centro de Práticas Integrativas: avanços e desafios.

O estudo envolveu, também, consulta às fontes documentais constituídas por: atas das reuniões do Conselho Municipal de Saúde de Uberlândia dos anos de 2012 e 2013; relatórios das Conferências Municipais de Saúde de 2011 e 2015 ( $6^{\underline{a}}$ e $7^{\text {a }}$ conferências); relatórios das $11^{\mathrm{a}}, 12^{\mathrm{a}}$, $13^{\mathrm{a}}$ e $14^{\mathrm{a}}$ Conferências Nacionais de Saúde; leis municipais, oㅡ 11.309 de 18 de fevereiro de 2013 e lei no 11.334, de 27 de março de 2013; veto à proposição de lei no 997/12; planos municipais de saúde de Uberlândia dos anos de 2010, 2014 e 2018; resolução no 478, de 7 de agosto de 2013 do Conselho Nacional de Saúde (CNS); site do Núcleo de Práticas Integrativas que estava vigente como meio de informação na época da implantação e o site da Prefeitura Municipal de Uberlândia.

Esse estudo integra a pesquisa de mestrado intitulada "Práticas Integrativas e Complementares na Promoção da Saúde: Perspectivas de Trabalhadores de Centro de Referência (Uberlândia-MG)", autorizada pela Prefeitura Municipal de Uberlândia e aprovada por Comitê de Ética sob no $\mathrm{CAAE}$ 79943617.0.0000.5154 e parecer ํㅜ 2.447.949.

Os participantes foram esclarecidos sobre objetivos e métodos e manifestaram consentimento em termo específico. As entrevistas ocorreram em local definido pelos participantes, com condições de sigilo e privacidade. O processo de validação do estudo envolveu a devolutiva das entrevistas aos participantes e a socialização dos resultados obtidos (TONG; SAINSBURY; CRAIG, 2007). Os trechos das entrevistas são seguidos pela indicação do número atribuído ao participante pela ordem de realização das entrevistas.

\section{RESULTADOS E DISCUSSÃO}

\section{Experiências embrionárias na comunidade}

A introdução de um novo modelo de saúde no SUS, mesmo que respaldado por uma política nacional, é um desafio para os defensores dessas novas racionalidades médicas (SANTOS; TESSER, 2012). Inúmeras são as dificuldades enfrentadas nos municípios para que a população 
tenha um efetivo acesso a esses atendimentos. Estudos apontam que a sensibilização dos gestores é fundamental para se conseguir um bom e efetivo funcionamento de um programa de práticas integrativas e complementares de saúde em âmbito municipal (BILHARINHO JÚNIOR, 2013; SANTOS et al., 2011).

Em Uberlândia-MG, uma experiência pioneira com atendimento em práticas integrativas de modo gratuito aconteceu anteriormente à PNPIC por meio de uma iniciativa de voluntários. Uma organização espírita, o Lar Fabiano de Cristo, nos anos 1980, objetivando promover a saúde das crianças de bairro periférico da cidade, começou a oferecer, graças à atuação de médica voluntária, consultas em homeopatia. Houve demandas para abranger os adultos nesses atendimentos, o que ocorreu com inserção de outros voluntários na área da fitoterapia. Tal grupo foi denominado de "Grupo Saúde".

[...] eu comecei a atender lá como voluntária, como homeopata e começou a vir adultos também nesse Grupo Saúde que, inicialmente, a gente chamou assim para ser atendido em diversas modalidades (ENT 12).

Devido ao crescimento desse projeto, em 1991, esses voluntários procuraram a prefeitura e no local foi instalada uma unidade de saúde.

[...] teve a ideia [...] de agruparmos e virar realmente um posto de saúde da prefeitura [...] aí teve a parceria da prefeitura, a universidade com os alunos, na classificação de plantas e de fazer uma pesquisa junto à comunidade e teve também até a horta (ENT 12).

A vocação e o envolvimento com a fitoterapia, inclusive com o plantio de uma horta com várias espécies de plantas medicinais, propiciaram a participação da Universidade Federal de Uberlândia (UFU) como instituição parceira, por meio de um programa de extensão. A partir de 1994 passou a ser desenvolvida a pesquisa denominada Projeto Semente. Este projeto envolvia a manipulação de medicamentos fitoterápicos e pesquisa junto aos usuários da unidade de saúde do bairro sobre os problemas de saúde que acometiam os moradores. A partir desses dados, realizou-se uma pesquisa na literatura sobre plantas medicinais e, baseando-se na experiência de duas raizeiras e um médico fitoterapeuta, foram desenvolvidos oito fitoterápicos para auxiliar no tratamento das seguintes doenças: diabetes, diarreias agudas e crônicas, afecções reumáticas, hipertensão arterial, dispepsias, amigdalites, faringites e estomatites, infecções do trato respiratório, gastrites e úlceras (DECHICHI; BARBOSA; ROSA, 1996).

Como já existia a horta de plantas medicinais, o objetivo era o atendimento, a manipulação dos fitoterápicos e a distribuição para a população. Porém, a regularização, da instituição para manipulação de fitoterápicos, requeria a aprovação junto à vigilância sanitária, a edificação de um local que atendesse todas as normas vigentes, o que demandava elevado investimento financeiro.

Diante dessas dificuldades, houve a desvinculação do Lar Fabiano de Cristo como uma unidade de saúde, pois, segundo a entrevistada, "tinha que ir atrás de organizar e o local tinha que passar por muitas reformas e a parte financeira pegou nesse momento." (ENT 12). Em decorrência, o projeto foi extinto no final da década de 1990 devido à falta de investimentos em uma estrutura adequada e de um programa para viabilizar a manipulação e a distribuição das medicações fitoterápicas.

As medicações fitoterápicas possibilitam a utilização de recurso local disponível, com a oferta de uma assistência à saúde eficaz e de qualidade e representam uma nova opção medicamentosa de boa aceitação e baixo custo (SILVA et al., 2006). Assim como em Uberlândia-MG, o início da fitoterapia na rede pública da cidade de Campinas-SP, acontece no início dos anos 1990, mas diferentemente do município mineiro, o projeto teve seguimento, apesar dos desafios enfrentados (SILVA, 2012). As experiências surgidas nessa época foram pioneiras no país, cabendo destacar também os municípios do Rio de Janeiro - RJ, Distrito Federal, Curitiba - PR e Fortaleza - CE, esta última considerada o berço da farmácia viva no Brasil (BRASIL, 2012).

Todo esse movimento da fitoterapia estava em sintonia com as discussões nacionais em torno da reforma sanitária e o direito à saúde. As iniciativas proporcionaram a ampliação da abordagem do processo saúde-doença e a disseminação de novos paradigmas, abrindo espaço para as práticas integrativas no campo da saúde (ISCHKANIAN; PELICIONI, 2012).

Além da experiência com a fitoterapia nos anos 1990, os atendimentos das práticas integrativas nas áreas de homeopatia e acupuntura principiaram na rede pública de Uberlândia-MG antes da implantação do Programa Municipal de Práticas Integrativas e Complementares (PMPIC). O serviço 
de acupuntura começou a ser ofertado, em 2010, no Centro de Reabilitação Municipal (CEREM), uma unidade multiprofissional de atendimentos de média complexidade que contava com um profissional acupunturista, o que gerava uma extensa lista de espera (PEREIRA; VILELA, 2011). Além disso, havia na rede mais dois profissionais que realizavam atendimentos em acupuntura:

\begin{abstract}
[...] pioneiramente duas fisioterapeutas, começaram a fazer acupuntura porque tinham formação na área, mas eram contratadas no município como fisioterapeutas da área de reabilitação. Então, isso acaba gerando uma complicação para esse profissional que tem outra formação executar essa sua formação dentro da rede, porque isso pode ser desvio de função. [...] elas tentaram fazer isso no início por algum tempo, mas não conseguiram manter esse serviço, ficou parado por um tempo (ENT 11).
\end{abstract}

A acupuntura foi regulamentada no Brasil, em 1984, de modo multiprofissional com o projeto de lei Federal $n^{\circ}$ 3838, mas somente em 1999, por meio da portaria 1230/GM, esse atendimento começa a ser oferecido pelo SUS, pela inserção do procedimento na tabela do Sistema de Informações Ambulatoriais do Sistema Único de Saúde (SIA/SUS) da consulta médica em acupuntura. Contudo, essa portaria centralizava o atendimento pelos médicos, impossibilitando que outros profissionais pudessem ser incluídos no contexto, o que só ocorreu com a PNPIC em 2006 (PEREIRA; VILELA, 2011).

A homeopatia, além do seu início no Projeto Semente, também já era uma especialidade oferecida na rede SUS desde 2005. A cidade já contava com esses atendimentos em um Centro de Atenção Psicossocial (CAPS) e em uma Unidade Básica de Saúde (UBS).

A homeopatia é reconhecida como especialidade médica desde 1980 e as normas de atendimento nos serviços públicos foram estabelecidas pela resolução n $4 / 88$ pela Comissão Interministerial de Planejamento e Coordenação das Ações de Saúde (CIPLAN), em 1988. O MS inseriu a consulta médica em homeopatia na tabela SIA/SUS em 1999 (BRASIL, 2015).

\title{
O processo de implantação das PICS: luta pela institucionalização
}

Embora as experiências embrionárias tenham ocorrido desde a década de 1990, o processo de institucionalização das PICS em âmbito municipal tem como marco a criação do Programa Municipal de Práticas Integrativas e Complementares de Saúde (PMPICS) por meio da lei no 11.309, de 18 de fevereiro de 2013. Essa lei já havia sido vetada em gestão municipal sob a alegação de já existirem atendimentos em homeopatia e acupuntura, de haver outras ações prioritárias previstas no orçamento e da compreensão de que essa matéria deveria ser de iniciativa do poder executivo devido à repercussão no orçamento sendo, portanto, inconstitucional (UBERLÂNDIA, 2012). Tal fato evidencia os tensionamentos e relações de poder que permeiam a implantação das políticas de saúde, especialmente as PICS (ANDRADE; COSTA, 2010).

Com a mudança de governo, houve uma articulação do prefeito eleito com a Câmara Municipal e o presidente da Câmara promulgou a lei. Não havia até então planejamento para a inclusão dessas práticas na rede SUS. Essa era uma proposta requerida por vários grupos da sociedade civil, como relatado por um dos entrevistados:

\begin{abstract}
Antes de 2013, a gente começou a se reunir com a sociedade civil. Vários setores, profissionais de saúde, usuários, para poder discutir e elaborar uma proposta, um projeto de lei de práticas integrativas para o município. [...] Nós nos reunimos na Central de Movimentos Populares, [...] ONGs que tinham atividades afins, representantes da Universidade Federal, [...] o proprietário da IPGU (Instituto de Pós-Graduação) que faz essa formação em PICS aqui no município, a parte indígena, enfim, era bem diversificado os participantes desse grupo (ENT 11).
\end{abstract}

A nova administração convidou o coordenador adjunto da Comissão Intersetorial de Práticas Integrativas e Complementares no SUS (CIPICSUS) do Conselho Nacional de Saúde (CNS), representava da Central de Movimentos Populares, para implantar e coordenar o Núcleo de Práticas Integrativas e Complementares de Saúde em Uberlândia. Neste sentido, é fundamental reconhecer a importância das experiências da Central de Movimentos Populares e do CNS na estruturação das PICS no município.

O CNS desempenhou papel fundamental na construção da PNPIC. Desde o ano de 2000, o CNS incluiu, nas conferências nacionais, a necessidade da incorporação de novas racionalidades médicas

DOI: http://dx.doi.org/10.14393/Hygeia153246912 Hygeia 15 (32): 149 - 163, junho/2019 página 153


no âmbito do SUS e propôs, na 11aㅡ Conferência Nacional de Saúde, a inserção das práticas de acupuntura e homeopatia no SUS (CONFERÊNCIA NACIONAL DE SAÚDE, 2001). A 13a Conferência, em 2008, estabeleceu como um desafio implementar a PNPIC no SUS com pactuações orçamentárias e recursos financeiros para a sua execução e incluir as práticas integrativas no acesso à assistência farmacêutica (CONFERÊNCIA NACIONAL DE SAÚDE, 2008). Em 2012, as propostas voltaram-se à criação de núcleos municipais de práticas integrativas e complementares em saúde com o reconhecimento da Terapia Comunitária como política pública e implantação da PNPIC na atenção básica (CONFERÊNCIA NACIONAL DE SAÚDE, 2012).

Assim, a iniciativa de criação do PMPICS em Uberlândia está em sinergia com os debates e propostas de ações das conferências nacionais de saúde, evidenciando a importância da participação popular e do controle social na construção das políticas de saúde.

Com a criação do PMPICS, houve a necessidade de regulamentação por meio de decreto, o que se desdobrou na implantação do Núcleo de Práticas Integrativas e Complementares em Saúde (UBERLÂNDIA, 2013). Contudo, o núcleo não foi inserido no organograma da secretaria municipal de saúde como os demais programas. Uma das alegações foi a necessidade de modificação da lei orgânica:

[...] mas tem esses entraves burocráticos, esses entraves dentro da própria secretaria [...] nós não conseguimos colocar um organograma das PICS dentro da secretaria e isso é fundamental para um programa. No que diz respeito a fazer lei, a fazer organograma, a gente fazia tudo isso, e tudo isso ficava engavetado (ENT 11).

O programa teve início com poucas contratações e envolvimento de profissionais da própria rede SUS com formação na área e interesse em trabalhar com as PICS:

[...] criamos um decreto que regulamentou toda essa política no município e conseguimos contratar alguns profissionais, via FUNDASUS (Fundação Saúde do Município de Uberlândia) e conseguimos, também, locar servidores que já estavam na prefeitura, servidores municipais que tinham conhecimento de alguma terapia e outros que tinham interesse em trabalhar com as práticas integrativas (ENT 8).

Com uma equipe formada, começou um trabalho de divulgação e sensibilização dos profissionais de saúde, gestores e da população:

[...] nós começamos um trabalho de conscientização da população, uma conscientização dos trabalhadores da área da saúde, uma conscientização do gestor [...]são conteúdos e práticas de saúde que eram desconhecidas pela população e pelos próprios profissionais de saúde (ENT 10).

O intenso trabalho de divulgação desenvolvido em todas as unidades de saúde vinculadas ao governo municipal, envolveu a realização de reuniões com as coordenações e eventos. $O$ evento chamado 'SUS em Movimento' percorreu os distritos sanitários realizando palestras e atendimentos com as práticas no intuito de divulgação e envolvimento dos profissionais, coordenadores e da população em geral.

Como forma de estruturar as PICS e obter recursos para a implantação do programa, o Núcleo de Práticas Integrativas apresentou proposta para concorrer em um edital, lançado pelo Ministério da Saúde (MS) destinado às secretarias estaduais e municipais de saúde para seleção de projetos de Arranjo Produtivo Local (APL), conforme a Política Nacional de Plantas Medicinais e Fitoterápicos (PNPMF) (BRASIL, 2013).

A PNPMF objetiva garantir à população brasileira o acesso seguro e o uso racional de plantas medicinais e fitoterápicos, promovendo o uso sustentável da biodiversidade, o desenvolvimento da cadeia produtiva e da indústria nacional. Esta política prevê a formação de APLs, vinculados ao setor de fitoterápicos compreendidos como diversos tipos de aglomerações produtivas (BRASIL, 2006).

Os arranjos produtivos locais constituem uma importante estratégia de desenvolvimento territorial por promover a articulação, interação, cooperação e aprendizado de empreendimentos de um mesmo ramo entre si e com demais atores locais como, o governo, instituições locais de pesquisa, ensino e instituições de crédito, além de valorizar os saberes locais (FERREIRA et al., 2017). Os APLs contribuem, ainda, para o reconhecimento da biodiversidade do país, para identificação e mobilização das práticas populares existentes nos diversos territórios e a superação da dicotomia entre conhecimento tradicional e conhecimento científico (CASTRO; FIGUEIREDO, 2019). 
A cadeia produtiva das plantas medicinais e dos fitoterápicos se inicia com o conhecimento popular e tradicional, envolve o cultivo e o manejo e a produção de fitoterápicos, passa pela atenção à saúde e assistência farmacêutica até a dispensação (BRASIL, 2006; TORRES, 2017). O edital lançado pelo MS objetivava apoiar e consolidar o fortalecimento de APLs no âmbito do SUS, com a finalidade de fortalecer a assistência farmacêutica e o complexo produtivo em plantas medicinais e fitoterápicos nos municípios e estados, contribuindo para ações transformadoras no contexto da saúde, ambiente e condições de vida da população (BRASIL, 2013).

As melhores propostas foram comtempladas com recurso financeiro para implantação dos projetos. A proposta enviada por Uberlândia foi selecionada, conforme a Portaria № 2.461, de 22 de outubro de 2013 que aprovou o repasse desse recurso para essa finalidade.

A área destinada à formação do horto municipal proposta no projeto do APL enviado ao MS é de 4 hectares e destina-se ao cultivo orgânico de plantas medicinais. Localiza-se em uma fazenda da Fundação de Excelência Rural de Uberlândia (FERUB) e foi escolhida por atender aos critérios da PNPMF: livre de contaminação de agrotóxicos, com boa disponibilidade e qualidade de água. Chegou-se a implantar esse horto e o plantio de várias espécies de plantas medicinais, mas não foi dada a continuidade ao projeto por inúmeras dificuldades:

\begin{abstract}
[...] o município tem um espaço de 13 hectares que pertence hoje às PICS, para que fosse implantado esse horto. Esse horto chegou a ser implantado, mas por falta de vontade, de pessoas para trabalhar dentro desse horto, de materiais e equipamentos de manutenção (...) nunca saiu da gaveta, sempre eles arrumavam um entrave para não levar isso adiante, para não levar para a câmara para ser votado (ENT 10).
\end{abstract}

Para a estruturação e implantação da farmácia para a produção de medicamentos fitoterápicos, homeopáticos e de outros produtos de uso em saúde, havia o respaldo de verbas da Secretaria Estadual de Saúde para a criação da 'Farmácia Viva', juntamente com uma planta baixa préaprovada. Contudo, esse recurso acabou sendo devolvido por não terem conseguido realizar modificações e aprovações devidas dentro do prazo:

[...] já vinha uma planta baixa estruturada e pré-aprovada, e aí teria que passar pelos trâmites locais, da vigilância sanitária, fazer as modificações necessárias em função da área, do local escolhido. Enfim, esse trâmite demorou tanto, tanto que a gente acabou perdendo esse recurso da secretaria de estado, isso acabou contribuindo para inviabilizar a execução do projeto (ENT 11).

Apesar do recebimento da verba do MS destinada ao projeto do APL, a fitoterapia não se estruturou em decorrência de dificuldades burocráticas para compra de equipamentos e, especialmente, falta de aprovação de legislação.

Com o projeto a gente precisava da lei de implementação da fitoterapia. Então, a gente fez um pré-projeto [...], isso foi para o jurídico e acabou ficando emperrado no jurídico, muito, muito tempo, aí mudou a gestão[...] o processo começava tudo de novo. A gente elaborava as minutas, isso era levado para o jurídico e ficava esse bate e volta. [...] Dentro da secretaria de saúde nós tivemos nessa gestão, dois secretários de saúde, tudo isso dificultou o processo (ENT 11).

Tal processo deve ser entendido de modo contextualizado, pois as chamadas "dificuldades burocráticas e jurídicas" reportadas pelos entrevistados trazem à tona os conflitos entre a racionalidade médica hegemônica e as PICS. Andrade e Costa (2010), ao analisar a construção da PNPIC, enfatizam os tensionamentos das racionalidades e os desafios postos à institucionalização da política pública. Chamam a atenção para o fato de que "a construção da política pública [...] atua face ao pluralismo terapêutico presente entre os brasileiros - e usuários do SUS -, no interior do qual convivem diferentes sistemas e modalidades médicas, crenças e itinerários de saúde." (ANDRADE; COSTA, 2010, p. 502).

Em face às críticas ao modelo médico hegemônico, Tesser e Sousa (2012) destacam as afinidades da atenção primária, da atenção psicossocial e das práticas integrativas, dentre as quais destacamse: abordagem familiar e comunitária, compreensão dos sujeitos em seus contextos familiares e sociais, estímulo à auto-cura, abordagens ampliadas da saúde e do processo de vida, valorização de saberes e práticas não-biomédicos.

Tais afinidades contribuem para a compreensão das potencialidades da territorialização no modelo de atenção à saúde. A territorialização da saúde, preconizada pelo SUS para organização das práticas e ações em saúde, é imprescindível para a garantia do direito à saúde, integralidade da atenção e o 
pluralismo terapêutico. Os vínculos construídos pelas equipes de saúde com a comunidade podem atuar como elementos facilitadores do reconhecimento dos saberes populares e incentivo às novas práticas de cuidado. (FARIA, 2013).

Assim, no processo de implantação e sedimentação das PICS em Uberlândia, a inserção na atenção básica ocupava lugar estratégico. Contudo, segundo os participantes do estudo, esta foi um dos principais desafios enfrentados e para superá-lo, as ações principiaram com a implantação das PICS nos Núcleos de Apoio à Saúde da Família (NASF) e a capacitação de agentes comunitários de saúde (ACS).

A acupuntura foi inserida nos NASFs, aumentando o número de unidades atendidas e a homeopatia regionalizada em algumas Unidades Básicas de referência. Contudo, o número reduzido de profissionais ainda representa uma barreira para a inclusão dessas práticas na atenção básica, que é e uma das propostas apresentadas na $7^{\text {a }}$ Conferência Municipal de Saúde, que propõe para gestão municipal "Implementar e ampliar as PICS em todas as unidades da Rede Municipal de Saúde tanto da área urbana quanto da área rural" (CONFERÊNCIA MUNICIPAL DE SAÚDE DE UBERLÂNDIAMG, 2015).

Outra ação na atenção básica foi a capacitação de ACS nas PICS para o conhecimento e uso das potencialidades das plantas medicinais e fitoterapia como terapêutica complementar. A ação abrangeu todo o distrito sanitário sul, com total de 21 equipes saúde da família (ESF) e contou com a participação de profissionais e coordenações das equipes.

[...] para que eles pudessem fazer orientações e identificar inclusive o uso pela população, começar a entrar isso também no universo das perguntas dos agentes, do diagnóstico deles na rede e fazer algumas orientações também para essas pessoas (ENT 9).

Apesar da intenção da gestão de contratação de trabalhadores para ampliar a oferta de atendimento das PICS, chegando a incluir essas vagas em um processo seletivo, estas contratações não ocorreram. O município vivia um momento político conturbado em que o Ministério Público (MP) questionava a legalidade da fundação municipal (FUNDASUS) criada para o gerenciamento da saúde no município. Embora o processo tenha ocorrido, não se efetivaram as contratações e a fundação acabou sendo extinta. Uberlândia, assim como outros municípios brasileiros, vive os desafios da contratação de trabalhadores por meio de terceirizações, o que incide na manutenção dos serviços e na gestão do trabalho, especialmente na rotatividade, insegurança dos trabalhadores e ausência de plano de carreiras (SANTINI et al., 2017)

Foi uma época de muita insatisfação para o funcionalismo público, principalmente no final do mandato, com crise financeira e incertezas gerando ansiedades e descontentamento. Tudo isso refletiu, também, no modo como esses trabalhadores receberam a implementação dessa nova política.

Então, você chega para falar para os funcionários que estavam extremamente insatisfeitos por causa de outras coisas, falando dos benefícios das práticas e o pessoal estava preocupado se iam receber ou não, se tinha emprego ou não tinha (ENT 4).

Sem profissionais para atendimento em PICS em toda a atenção básica e sem a implementação da fitoterapia pelos entraves burocráticos e políticos, decidiu-se pela implantação de um centro de referência - o Centro de Referência em Práticas Integrativas e Complementares em Saúde (CRPICS) - no qual os profissionais pudessem atender os pacientes referenciados de outras unidades de saúde. Para tanto, "o objetivo era ser um lugar mais centralizado, que tivesse acesso de ônibus para todos os lugares da cidade" (ENT 7). O CRPICS, inaugurado em março de 2016, foi localizado em região central de Uberlândia.

Uma das frentes nesse processo foi a realização de cursos de formação e capacitação. Um curso de especialização em homeopatia foi promovido pela Secretaria Municipal de Saúde e o Núcleo de Homeopatia do PMPIC.

[...] na época teve um curso de homeopatia, de especialização que foi em parceria com a secretaria municipal de saúde [...] foi um curso destinado aos médicos [...] atendendo pacientes do SUS (ENT 9).

O curso de prescritor em fitoterapia que estava previsto como meta no projeto inicial do APL não ocorreu. Apesar do processo de implantação das PICS em Uberlândia ter sido amparado pelo projeto 
APL, a fitoterapia não avançou conforme previsto. Ainda é necessário estruturar a farmácia e o horto de plantas medicinais para garantir a assistência farmacêutica por meio da produção, prescrição e dispensação das plantas medicinais e fitoterápicos na rede SUS, conforme proposta apresentada na APL.

E aí eu falo isso com uma tristeza e uma frustação muito grande, que a fitoterapia acabou ficando de fora [...]. Por que? Por que não tinha um médico em formação em fito para dar esse arranque? Não sei. Como teve a parte da homeopatia, que é médica, a antroposofia, que é médica, então será que faltou esse respaldo? (ENT 11).

A PNPIC trouxe para a população mais uma alternativa para o cuidado com a saúde, propiciando um acesso a práticas terapêuticas anteriormente disponíveis apenas no setor privado. A inserção dessas práticas no SUS representa a garantia do princípio da universalidade e, também, um meio terapêutico eficaz e seguro diante da crescente insatisfação com o sistema biomédico. A garantia do acesso às PICS foi exposta pelos entrevistados:

[...] todo mundo tinha que pagar particular a sessão e o trabalho. As pessoas gostam muito quando sabem que tem pelo SUS, e falam "-Nossa, isso tem pelo SUS?" (ENT 2).

Mesmo com todos esses problemas ocorridos no processo de implantação das PICS em Uberlândia, a cidade é considerada referência:

Uberlândia hoje é referência nacional. E tem vários municípios que tem a política das práticas integrativas há mais de dez anos e ainda não funciona como Uberlândia. [...] Aqui é amparado por todos os requisitos: o projeto, a lei municipal e profissionais (ENT 6).

A estruturação e fortalecimento da atenção em PIC na cidade caminha em consonância com diretrizes propostas na PNPIC, incentivando a inserção das práticas em todos os níveis de atenção priorizando a atenção primária, estabelecendo um caráter multiprofissional, promovendo capacitações e formações para profissionais no SUS, divulgando e informando conhecimentos básicos da PICS para profissionais de saúde, gestores e usuários do SUS e buscando parcerias (BRASIL, 2015).

Com o apoio de uma lei municipal e com essas diretrizes estabelecidas, as práticas integrativas ganharam seu espaço no sistema de saúde local, garantindo o acesso da população a uma terapêutica de caráter holístico e que estimula $O$ uso de métodos naturais de prevenção e recuperação, além da promoção do cuidado (ISCHKANIAN; PELICIONI, 2012; SARAIVA; FERREIRA FILHA; DIAS, 2011).

\section{O Centro de Práticas Integrativas: avanços e desafios}

Atualmente, o Núcleo de Práticas Integrativas possui uma coordenadora, responsável pelo CRPICS, o horto municipal de plantas medicinais e as práticas desenvolvidas na atenção básica. A coordenadora exerce a função de coordenadora de ações temáticas, pois não há no organograma da secretaria de saúde denominação específica para as PICS. A formação de prescritores de fitoterapia ainda não ocorreu conforme o projeto proposto da APL, não há funcionários para cuidar do horto e a farmácia foi descrita pelos participantes como 'um sonho'.

O CRPICS oferece atendimento em homeopatia, acupuntura, medicina antroposófica, Reiki, dança circular e grupos de meditação. Possui um total de doze profissionais, a maioria possui várias formações em práticas integrativas e atua no centro desde sua inauguração.

O sistema de agendamento dos usuários é feito através do encaminhamento de um profissional de nível superior da unidade de saúde a qual o usuário está vinculado. Para a acupuntura e homeopatia, cadastra-se o pedido e a consulta é marcada seguindo uma fila de espera. Nas demais práticas, após o pedido de encaminhamento, a unidade de saúde envia um e-mail ao CRPICS e o próprio Centro agenda essa consulta.

A acupuntura e a homeopatia, segundo a coordenadora, são as práticas que mais têm pacientes na fila de espera: 1500 e 400 pessoas na fila de espera, respectivamente. Além da atenção básica, o CRPICS também recebe encaminhamentos de CAPS.

A demanda para as práticas vem aumentando, apesar do desconhecimento de muitos profissionais de saúde quanto à oferta dessas terapias pelo SUS. A crescente procura das PICS pode estar 
relacionada ao alto grau de satisfação dos usuários que recebem esses atendimentos e, também, à insatisfação difusa e crescente com a abordagem caracterizada como mecanicista, intervencionista, restrita aos sintomas e progressivamente mais impessoal da medicina hegemônica. De maneira geral, existe satisfação dos usuários quando percebem que são vistos de uma maneira integral e não reduzidos à sinais e sintomas (LUZ, 2005; TESSER; SOUSA, 2012).

Uma das estratégias para a consolidação da PMPIC é a inclusão das PICS em toda a atenção primária para que o usuário tenha acesso à essas práticas na sua própria unidade de saúde e o centro de referência funcione como um centro de formação e capacitação. Para tanto, são necessários investimentos em recursos humanos, na capacitação profissional e, também, disponibilização de profissionais capacitados em PICS.

Como não existe financiamento específico para as PICS, a coordenação do CRPICS, de maneira isolada e com a ajuda de parceiros da rede privada, promoveu cursos de formação em algumas práticas, sem ônus para a administração pública, no intuito de inserir esse tipo de atendimento em mais unidades da atenção primária.

Atualmente, após oferta de formação em auriculoterapia e dança circular para mais de 100 profissionais de saúde, se conseguiu disponibilizar essas práticas em mais unidades de saúde. Em outra parceria com a rede privada, foi oferecida formação em Reiki nível 1 para profissionais da rede pública visando capilarizar esse atendimento em mais unidades de saúde. Segundo dados registrados no CRPICS, referente aos quatro primeiros meses de 2018, 25 unidades de saúde produziram algum tipo de atendimento em PICS até o mês de abril e 47 unidades possuíam um profissional habilitado para oferecer alguma prática, um avanço em relação ao ano anterior em que, apenas seis unidades básicas tinham profissionais de PICS atuando. O objetivo é que todas as unidades da atenção primária ofereçam pelo menos uma das PICS.

De acordo com esses dados, após as formações oferecidas aos profissionais, o número de atendimentos em auriculoterapia na rede SUS de Uberlândia aumentou de 769 atendimentos/mês (em janeiro de 2018) para 1497 atendimentos/mês (em abril). Em relação à dança circular, com a capacitação oferecida, o registro dessa prática aumentou de 17 atendimentos/mês para 26 no mesmo período.

Os desafios enfrentados para a institucionalização das PICS no SUS são muitos. Há uma carência de recursos humanos capacitados, não existe um financiamento adequado e falta uma estrutura para o desenvolvimento de novas práticas e serviços (SANTOS; TESSER, 2012). Não existem incentivos para o gestor municipal implantar e manter serviços. O edital do APL, que apoiou iniciativas locais para a produção local de fitoterápicos, e outros dois editais, um que apoia pesquisadores de instituições de ensino em projetos de avaliação clínica e de serviços de PICS e outro que apoia os serviços de PICS no município ou estado, para aquisição de insumos, material didático e processos de educação permanente foram um dos poucos incentivos do MS nesta seara (LINS; NUNES; AROUCHA, 2014).

Outra dificuldade encontrada é em relação aos próprios profissionais de saúde cuja formação foi baseada no modelo biomédico. Eles foram acostumados a pensar e agir de acordo com modelos essencialmente conservadores de conhecimentos fragmentados, centrados na doença e na figura do médico. É fundamental que haja preparo político e técnico para que esses profissionais atuem com as PICS no SUS de modo a superar as resistências em relação às PICS e favorecer o encaminhamento dos usuários para esses atendimentos. Urge intensificar a formação de profissionais em sintonia com as diretrizes do SUS e com conhecimento em saúde coletiva, uma educação que supere a visão cartesiana da mente dissociada do corpo e do mundo social das pessoas (AZEVEDO; PELICIONI 2012; SAMPAIO, 2014).

A fitoterapia desempenhou importante papel no desenvolvimento do PMPCIS de Uberlândia, em decorrência da liberação de recursos via APL. Contudo, após mais de quatro anos do recebimento do recurso federal, o município não conseguiu implantar a "Farmácia Viva" e garantir a produção, prescrição e dispensação de medicamentos fitoterápicos, homeopáticos e outros produtos de uso em saúde, conforme os objetivos do APL local. De acordo com os entrevistados, muitos entraves decorreram de divergências políticas e econômicas. O sistema hegemônico da cultura da doença, no seu aspecto mercantil da indústria farmacêutica, que estimula cada vez mais o consumo frenético de novas medicações, representa uma forte oposição e à estruturação desse modelo de assistência (MARTINS, 2014). 
Apesar da definição de medicina integrativa estar relacionada à integração com a medicina convencional, com o objetivo de oferecer melhor cuidado ao paciente, dando a estes a oportunidade de escolha pela forma mais adequada para seu tratamento, esse processo de institucionalização das PICS tem encontrado muitos obstáculos interpostos pela medicina socialmente hegemônica (LUZ, 2005; OTANI; BARROS, 2011).

A ciência biomédica amparada na tecnologia, farmacologia e no método científico se opõe à inserção das PICS em espaços institucionais alegando a falta de evidências científicas. O Conselho Federal de Medicina (CFM), após a inclusão de novas PICS no SUS, manifestou por meio de uma nota dirigida à população e aos médicos sua posição contrária a essa medida alegando que tais práticas alternativas não apresentam resultados e eficácia comprovados cientificamente; ignoram prioridades na alocação de recursos no SUS e que a prescrição e o uso de procedimentos e terapêuticas alternativos, sem reconhecimento científico, são proibidos aos médicos brasileiros.

Diante de tais argumentações, fica evidente o predomínio do pensamento curativista e de priorização da doença pelos representantes da categoria médica brasileira. Embora vários trabalhos publicados demonstrem a eficácia das medicinas integrativas e complementares como coadjuvantes em tratamentos de doenças crônicas, na prevenção, na promoção da saúde (GENTIL; ROBLES; GROSSEMAN, 2010; RODRÍGUEZ et al., 2011; OLIVEIRA, 2013; JOYCE; HERBISON, 2015; ALI; KATZ, 2015) e também na qualidade de vida (GREESON et al., 2008), a lógica biomédica tem prevalecido sobre a integralidade da atenção.

Os cuidados de saúde quando não tratam adequadamente os sintomas e não envolvem o paciente em uma aliança terapêutica, não podem ser considerados avançados. O cuidado integrativo amplia a variedade de opções dos pacientes e pode aumentar a probabilidade de sucesso em todos os níveis (ALI; KATZ, 2015).

\section{CONSIDERAÇÕES FINAIS}

A implantação da PNPIC no município de Uberlândia-MG representa um marco para efetivar práticas de cuidado distintas da hegemonia biomédica. O estudo revelou a existência de conflitos paradigmáticos que impactaram no ritmo da estruturação dessas práticas no município, principalmente em relação à fitoterapia.

A crescente demanda pelas PICS demonstra a satisfação do usuário com as práticas oferecidas e retrata a boa aceitação das PICS no município. A atuação de profissionais comprometidos e engajados no processo foi de fundamental importância para a criação do centro de referência em PICS. A constante luta e o engajamento desse grupo sedimentaram uma boa estrutura para essas práticas.

Os desafios ainda são muitos, e diante do quadro atual que se apresenta de crise política e econômica, a incorporação das PICS poderia ser considerada uma alternativa de baixo custo e de grande potencialidade para cuidar da saúde da população, seja na promoção da saúde, na cura ou na amenização do sofrimento.

As PICS têm um grande potencial para estimular mudanças de padrões de assistência à saúde, principalmente na Atenção Primária, sendo uma estratégia fundamental para sua sedimentação no SUS.

Embora a PNPIC represente a legitimação e institucionalização das PICS no SUS, ainda percebemos obstáculos para sua implantação. A falta de financiamento, o despreparo dos profissionais de saúde, que não tem na sua formação conteúdos de práticas integrativas, os interesses econômicos e supremacia do modelo biomédico em detrimento do cuidado humano são fortes entraves para propiciar um melhor acesso da população à essas práticas.

Outro desafio para a inclusão dessas práticas no SUS seria estabelecer um diálogo entre as diferentes práticas de saúde, fazendo uma integração desses saberes, objetivando oferecer melhor cuidado ao usuário, dando a este a oportunidade de decidir pela forma que considerar mais adequada para seu tratamento.

Existe a necessidade de ampliar a divulgação dos benefícios das PICS entre gestores, trabalhadores e usuários do SUS, evidenciando as experiências existentes para a superação dessa supremacia epistemológica e propiciar ampliação do acesso e a qualificação dos serviços na perspectiva da integralidade da atenção à saúde da população.

DOI: http://dx.doi.org/10.14393/Hygeia153246912 Hygeia 15 (32): $149-163$, junho/2019 página 159


É muito importante o desenvolvimento de estratégias para que essa política se fortaleça no município. O incentivo a adequações operacionais, um sistema de registro de informação eficaz e formas de avaliação eficientes são estratégias que viabilizam a produção de informações que serão relevantes para a divulgação e produção científica nesse campo, ajudando a fortalecer e respaldar essas novas racionalidades médicas contribuindo para que tais práticas se tornem mais respeitadas e conhecidas, e possam ser uma possibilidade terapêutica para toda a população brasileira. Espera-se que a compreensão da experiência do município mineiro possa contribuir para o enfrentamento dos desafios postos à sedimentação das PICS em âmbito nacional e valorizar a trajetória dos trabalhadores participantes do estudo.

\section{REFERÊNCIAS}

ALI, A.; KATZ, D. L. Disease prevention and health promotion: how integrative medicine fits. American Journal of Preventive Medicine, New York, v. 49, n. 5, p. 230-240, 2015. Disponível em: https://www.ncbi.nlm.nih.gov/pmc/articles/PMC4615581/pdf/nihms-711937.pdf. Acesso em: 20 mar. 2018. https://doi.org/10.1016/i.amepre.2015.07.019

AMADO, J.; FERREIRA, M. M. Usos e abusos da história oral. Rio de janeiro: FGV, 2006.

ANDRADE, J. T.; COSTA, L. F. A. Medicina complementar no SUS: práticas integrativas sob luz da Antropologia médica. Saúde e Sociedade, São Paulo, v. 19, n. 3, p. 497-508, setembro de 2010. Disponível em http://www.scielo.br/pdf/sausoc/v19n3/03.pdf. Acesso em: 10 ago. 2019. https://doi.org/10.1590/S0104-12902010000300003

AZEVEDO, E.; PELICIONI, M. C. F. Práticas integrativas e complementares de desafios para a educação. Trabalho Educação e Saúde, Rio de Janeiro, v. 9, n. 3, p. 361-378, nov./2011-fev./2012. Disponível em: http://www.scielo.br/pdf/tes/v9n3/v9n3a02.pdf. Acesso em: 18 jun. 2018. https://doi.org/10.1590/S1981-77462011000300002

BILHARINHO JUNIOR, C. R. Análise institucional e práticas integrativas e complementares em saúde: o caso do Lian Gong. In: L'ABBATE, Solange; MOURÃO, Lúcia C; PEZZATO, Luciane M. (org.). Análise institucional e saúde coletiva. São Paulo: Hucitec, 2013. p. 239-261.

BRASIL. Ministério da Saúde. Edital oo 01 de 24 de maio de 2013: seleção pública de projetos de arranjo produtivo local de plantas medicinais e fitoterápicos no âmbito do SUS. Brasília, DF: MS, 2013. Disponível em: http://portalarquivos2.saude.gov.br/images/pdf/2014/abril/02/Edital-APL2013.pdf. Acesso em: 28 maio 2018.

BRASIL. Ministério da Saúde. Portaria $n^{\circ} 702$, de 21 de março de 2018. Altera a Portaria de Consolidação no 2/GM/MS, de 28 de setembro de 2017, para incluir novas práticas na Política Nacional de Práticas Integrativas e Complementares - PNPIC. Brasília, DF: MS, 2018. Disponível em: http://bvsms.saude.gov.br/bvs/saudelegis/gm/2018/prt0702_22_03_2018.html. Acesso em: 14 ago. 2018.

BRASIL. Ministério da Saúde. Secretaria de Atenção à Saúde. Departamento de Atenção Básica. Política nacional de práticas integrativas e complementares no SUS: atitude de ampliação de acesso. 2. ed. Brasília, DF: MS, 2015.

BRASIL. Ministério da Saúde. Secretaria de Atenção à Saúde. Departamento de Atenção Básica. Práticas integrativas e complementares: plantas medicinais e fitoterapia na atenção básica. Brasília, DF: MS, 2012. Disponível em:

http://bvsms.saude.gov.br/bvs/publicacoes/praticas_integrativas_complementares_plantas_medicinais _cab31.pdf. Acesso em: 25 maio 2018.

BRASIL. Ministério da Saúde. Secretaria de Ciência, Tecnologia e Insumos Estratégicos.

Departamento de Assistência Farmacêutica. Política nacional de plantas medicinais e fitoterápicos. Brasília, DF: MS, 2006. Disponível em:

http://bvsms.saude.gov.br/bvs/publicacoes/politica_nacional_fitoterapicos.pdf. Acesso em: 25 maio 2018.

BRAUN, V.; CLARKE, V. Using thematic analysis in psychology. Qualitative Research in Psychology, London, v. 3, n. 2, p. 77-101, 2006. Disponível em: https://www.tandfonline.com/doi/abs/10.1191/1478088706qp063oa. Acesso em: 14 ago. 2018 https://doi.org/10.1191/1478088706qp063oa 
CASTRO, M. R.; FIGUEIREDO, F. F. Figueiredo Saberes tradicionais, biodiversidade, práticas integrativas e complementares: o uso de plantas medicinais no SUS. Hygeia, Uberlândia, MG, v. 15, n. 31, p. 56-70, mar. 2019. Disponível em:

http://www.seer.ufu.br/index.php/hygeia/article/view/46605/26405. Acesso em: 10 out. 2019. https://doi.org/10.14393/Hygeia153146605

CONFERÊNCIA MUNICIPAL DE SAÚDE UBERLÂNDIA, 7., 2015, Uberlândia, MG. Relatório final ... Uberlândia, MG: Prefeitura municipal, 2015.

CONFERÊNCIA NACIONAL DE SAÚDE, 11., 2000. Brasília, DF. Relatório final... Brasília, DF: Ministério da Saúde, 2001. Disponível em:

http://conselho.saude.gov.br/biblioteca/Relatorios/relatorio_11.pdf. Acesso em: 24 maio 2018.

CONFERÊNCIA NACIONAL DE SAÚDE, 13., 2008. Brasília, DF. Relatório final... Brasília, DF: Ministério da Saúde, 2008. Disponível em:

http://conselho.saude.gov.br/biblioteca/Relatorios/13cns_M.pdf. Acesso em 24 maio 2018.

CONFERÊNCIA NACIONAL DE SAÚDE, 14., 2012. Brasília, DF. Relatório final... Brasília, DF: Ministério da Saúde, 20012. Disponível em:

http://conselho.saude.gov.br/biblioteca/Relatorios/img/14_cns\%20relatorio_final.pdf. Acesso em: 24 maio 2018.

DECHICHI, M.; BARBOSA, M. A. S.; ROSA, L. F. Pesquisa e manipulação de medicamentos fitoterápicos no bairro Pacaembu. In: UNIVERSIDADE FEDERAL DE UBERLÂNDIA. Pró-Reitoria de Extensão Cultura e Assuntos Estudantis. Produção e extensão, cultura e assuntos estudantis da UFU 1993-1996. Uberlândia, MG: UFU,1996, p. 64-65.

FARIA, R. M. A territorialização da atenção primária à saúde no sistema único de saúde e a construção de uma perspectiva de adequação dos serviços aos perfis do território. Hygeia, Uberlândia, MG, v. 9, n. 16, p.131-147, jun. 2013. Disponível em: http://www.seer.ufu.br/index.php/hygeia/article/view/19501/12458. Acesso em: 17 out. 2019.

FERREIRA, L. L. C.; MATTOS, J. L. C.; OLIVEIRA, D. R.; BEHRENS, M. D. Incentivo governamental para Arranjos Produtivos Locais de Plantas Medicinais e Fitoterápicos no âmbito do SUS. Revista Fitos, Rio de Janeiro, v. 11, n. 1, p. 54-61, 2017. Supl. Disponível em:

https://www.arca.fiocruz.br/bitstream/icict/21131/2/leide_lene_coelho_et_all.pdf. Acesso em: 17 out. 2019. https://doi.org/10.5935/2446-4775.20170015

FERTONANI, H. P.; PIRES, D. E. P.; BIFF, D.; SCHERER, M. D. A. Modelo assistencial em saúde: conceitos e desafios para a atenção básica brasileira. Ciência e Saúde Coletiva, Rio de Janeiro, v. 20, n. 6, p. 1869-1878, 2015. Disponível em: https://www.scielosp.org/pdf/csc/2015.v20n6/1869-1878/pt. Acesso em: 15 out. 2019. https://doi.org/10.1590/1413-81232015206.13272014

GENTIL, L. B.; ROBLES, A. C. C.; GROSSEMAN, S. Uso de terapias complementares por mães em seus filhos: estudo em um hospital universitário. Ciência e Saúde Coletiva, Rio de Janeiro, v. 15, p. 1293-1299, 2010. Supl. 1. Disponível em: https://www.scielosp.org/pdf/csc/2010.v15suppl1/12931299/pt. Acesso em: 20 jun. 2018. https://doi.org/10.1590/S1413-81232010000700038

GREESON, J. M.; ROSENZWEIG, S.; HALBERT, S. C.; CANTOR, I. S.; KEENER, M.T.; BRAINARD, G. C. Integrative medicine research at an Academic Medical Center: patient characteristics and health-related quality-of-life outcomes. Journal of Alternative and Complementary Medicine, New York, v.14, n. 6, p. 763-767, 2008. Disponível em:

Https://www.ncbi.nlm.nih.gov/pmc/articles/PMC3153865/pdf/acm.2008.0114.pdf. Acesso em: 20 mar. 2018. https://doi.org/10.1089/acm.2008.0114

ISCHKANIAN, P. C.; PELICIONI, M. C. F. Desafios das práticas integrativas e complementares no SUS visando a promoção da saúde. Revista Brasileira de Crescimento e Desenvolvimento Humano, São Paulo, v. 22, n. 1, p. 233-238, ago. 2012. Disponível em:

http://www.revistas.usp.br/jhgd/article/view/44936. Acesso em: 10 mar. 2017. https://doi.org/10.7322/jhgd.44936

JOYCE J.; HERBISON G. P. Reik for depression and anxiety. The Cochrane Database of Systematic Reviews, Oxford, v. 3, n. 4, p. 1-36, Apr. 2015. Disponível em: https://www.ncbi.nlm.nih.gov/pubmed/25835541. Acesso em: 16 jun. 2018.

LINS, J. A. B. J.; NUNES, J. G.; AROUCHA, E. B. L. Um olhar trimembrado sobre a implantação de 
serviços de práticas integrativas e complementares em saúde. In: BARRETO, Alexandre F. (org.). Práticas integrativas em saúde: proposições teóricas e experiências na saúde e educação. Recife: Ed. UFPE, 2014. cap. 9, p. 155-174

LUZ, M.T. Cultura contemporânea e medicinas alternativas: novos paradigmas em saúde no fim do século XX. Physis, Rio de Janeiro, v. 15, p. 145-176, 2005. Supl. Disponível em: http://www.scielo.br/pdf/physis/v15s0/v15s0a08.pdf. Acesso em: 08 jun. 2017. https://doi.org/10.1590/S0103-73312005000300008

MARTINS, P. H. Prefácio. In: BARRETO, Alexandre F. (org.). Práticas integrativas em saúde: proposições teóricas e experiências na saúde e educação. Recife: Ed. UFPE, 2014. p. 7-12

MINAYO, M.C.S. O desafio do conhecimento. 12. ed. São Paulo: Hucitec, 2010.

OLIVEIRA, R. M. J. Efeitos da prática do reiki sobre aspectos psicofisiológicos e de qualidade de vida de idosos com sintomas de estresse: estudo placebo e randomizado. Orientador: José Roberto Leite. 2013. 165 f. Tese (Doutorado em Ciências) -- Escola Paulista de Medicina, Universidade Federal de São Paulo, São Paulo, 2013. Disponível em: http://repositorio.unifesp.br/handle/11600/22764. Acesso em 16 jun. 2018.

OTANI, M. A. P.; BARROS, N. F. A medicina integrativa e a construção de um novo modelo na saúde. Ciência \& Saúde Coletiva, Rio de Janeiro, v. 16, n. 3, p. 1801-1811, 2011. Disponível em: http://www.scielo.br/pdf/csc/v16n3/16.pdf. Acesso em: 20 abr. 2018. https://doi.org/10.1590/s141381232011000300016

PEREIRA, C. F.; VILLELA, W. V. Acupuntura na rede pública de saúde: uma análise sobre a organização e funcionamento na unidade de referência em Uberlândia-MG. Boletim do Instituto de Saúde, São Paulo, v. 13, n. 2, p. 156-161, 2011. Disponível em: http://periodicos.ses.sp.bvs.br/pdf/bis/v13n2/v13n2a08.pdf. Acesso em: 14 ago. 2018.

PETTRES, A. A; DA ROS, M. A. A determinação social da saúde e a promoção da saúde. Arquivos Catarinenses de Medicina, Florianópolis, v. 47, n. 3, p.183-196. jul./set. 2018. Disponível em: http://www.acm.org.br/acm/seer/index.php/arquivos/article/view/375/282. Acesso em: 15 out. 2019.

RODRÍGUEZ, L. D.; ARROYO-MORALES, M.; CANTARERO-VILANUEVA; I.; FÉRNANDEZ-LAO, C.; POLLEY, M.; FÉRNANDEZ-DE-LAS-PEÑAS, C. Uma sessão de Reiki em enfermeiras diagnosticadas com síndrome de Burnout tem efeitos benéficos sobre a concentração de $\lg A$ salivar e pressão arterial. Revista Latino-Americana de Enfermagem, Ribeirão Preto, v. 19, n. 5, set./out. 2011. Disponível em: http://www.scielo.br/pdf/rlae/v19n5/pt_10. Acesso em: 16 jun. 2018.

SAMPAIO, A. T. L. Educação em saúde: caminhos para formação integrativa. In: BARRETO, A. A. (org.). Práticas integrativas em saúde: proposições teóricas e experiências na saúde e educação. Recife: Ed. UFPE, 2014. cap. 6, p. 99-174.

SANTINI, S. M. L.; NUNES, E.F.P.A.; CARVALHO, B.G.; SOUZA, F.E.A. Dos 'recursos humanos' à gestão do trabalho: uma análise da literatura sobre o trabalho no SUS. Trabalho, educação e saúde, Rio de Janeiro, v. 15, n. 2, p. 537-559, ago. 2017. Disponível em: http://www.scielo.br/pdf/tes/v15n2/1678-1007-tes-1981-7746-sol00065.pdf. Acesso em: 10 mar. 2019.https://doi.org/10.1590/1981-7746-sol00065

SANTOS, F. A. S.; SOUSA, I. M. C.; GURGEL, I. G. D.; BENJAMIN, A. F.; BARROS, N. F. Política de práticas integrativas em Recife: análise da participação dos atores. Revista de Saúde Pública, São Paulo, v. 45, n. 6, p. 1154-1159, 2011. Disponível em: http://www.scielo.br/pdf/rsp/v45n6/2916.pdf. Acesso em: 11 jun. 2018.https://doi.org/10.1590/S0034-89102011000600018

SANTOS, M. C.; TESSER, C. D. Um método para a implantação e promoção de acesso às práticas integrativas e complementares na atenção primária à saúde. Ciência \& Saúde Coletiva, Rio de Janeiro, v. 17, n. 11, p. 3011-3024, 2012. Disponível em: http://www.scielo.br/pdf/csc/v17n11/v17n11a17.pdf. Acesso em: 25 maio 2018.https://doi.org/10.1590/S1413-81232012001100018

SARAIVA, A. M.; FERREIRA FILHA, M. O.; DIAS, M. D. As práticas integrativas como forma de complementaridade ao modelo biomédico: concepções de cuidadoras. Revista de Pesquisa: Cuidado é Fundamental, Rio de Janeiro, v. 3, n. supl., p.155-163, dez. 2011. Disponível em: http://www.seer.unirio.br/index.php/cuidadofundamental/article/view/1953/pdf_536. Acesso em: 23 maio 2018. 
SILVA, J. B. As práticas do uso de plantas medicinais e fitoterápicos por trabalhadores de saúde na atenção básica. Orientadora: Matumoto, Silvia. 2012. 155 f. Dissertação (Mestrado em Ciências) -Escola de Enfermagem de Ribeirão Preto, Universidade de São Paulo, Ribeirão Preto, 2012. Disponível em: http://www.teses.usp.br/teses/disponiveis/22/22133/tde-15012013-113218/pt-br.php. Acesso em: 25 maio 2018.

SILVA, M. I. G.; GONDIM, A. P. S.; NUNES, I. F. S.; SOUSA, F. C. Utilização de fitoterápicos nas unidades básicas de atenção à saúde da família no município de Maracanaú (CE). Revista Brasileira de Farmacognosia, João Pessoa, v.16, n. 4, p. 455-462, 2006. Disponível em:

http://www.scielo.br/pdf/rbfar/v16n4/a03v16n4.pdf. Acesso em: 10 out. 2019.

https://doi.org/10.1590/S0102-695X2006000400003

SOUZA, C. R; BOTAZZO, C. Construção social da demanda em saúde. Physis, Rio de Janeiro, v. 23, n. 2, p. 393-413, 2013. Disponível em: http://www.scielo.br/pdf/physis/v23n2/v23n2a05.pdf. Acesso em: 10 mar. 2018.https://doi.org/10.1590/S0103-73312013000200005

SOUSA, I. M. C.; BODSTEIN, R. C. A.; TESSER, C. D.; SANTOS, F. A. S.; HORTALE, V. A. Práticas integrativas e complementares: oferta e produção de atendimentos no SUS e em municípios selecionados. Cadernos de Saúde Pública, Rio de Janeiro, v. 28, n. 11, p. 2143-2154, nov. 2012. Disponível em: http://www.scielo.br/pdf/csp/v28n11/14.pdf. Acesso em: 11 jun. 2018. https://doi.org/10.1590/S0102-311X2012001100014

TELESI JUNIOR, E. Práticas integrativas e complementares em saúde, uma nova eficácia para o SUS. Estudos Avançados, São Paulo, 2016, v. 30, n. 86, p. 99-112, 2016. Disponível em: http://www.scielo.br/pdf/ea/v30n86/0103-4014-ea-30-86-00099.pdf. Acesso em: 11 jun. 2018.https://doi.org/10.1590/S0103-40142016.00100007

TESSER, C. D; SOUSA, I. M. C. Atenção primária, atenção psicossocial, práticas integrativas e complementares e suas afinidades eletivas. Saúde e Sociedade, São Paulo, v. 21, n. 2, p. 336-350, 2012. Disponível em: http://www.scielo.br/pdf/sausoc/v21n2/a08v21n2.pdf. Acesso em: 25 ago. 2017.https://doi.org/10.1590/S0104-12902012000200008

TONG, A.; SAINSBURY, P.; CRAIG, J. Consolidated criteria for reporting qualitative research (COREQ): a 32-item checklist for interviews and focus groups. International Journal of Quality in Health Care, Kidlington, v. 19, n. 6, p. 349-357. Disponível em:

https://academic.oup.com/intqhc/article/19/6/349/1791966. Acesso em: 25 ago.

2017.https://doi.org/10.1093/intghc/mzm042

TORRES, K. R. Os Arranjos produtivos locais no contexto da implementação da política e do programa nacional de plantas medicinais e fitoterápicos. In: OLIVEIRA, Carlos W. A et al. (org.). Arranjos produtivos locais e desenvolvimento, Rio de Janeiro: IPEA, 2017. p. 267-280. Disponível em: http://www.ipea.gov.br/portal/images/stories/PDFs/livros/livros/171010_livro_arranjos_produtivos.pdf. Acesso em: 17 jan. 2019.

UBERLÂNDIA (MG). Prefeitura Municipal. Lei no 11.334, de 27 de março de 2013. Altera dispositivo da lei N. -11.309 , de 18 de fevereiro de 2013, que "Autoriza a criação do Programa Municipal de Práticas integrativas e Complementares de Saúde - PMPICS, e dá outras providências". Uberlândia, MG: Prefeitura Municipal, 2013. Disponível em: https://leismunicipais.com.br/a/mg/u/uberlandia/leiordinaria/2013/1134/11334/lei-ordinaria-n-11334-2013-altera-dispositivo-da-lei-n-11309-de-18-defevereiro-de-2013-que-autoriza-a-criacao-do-programa-municipal-de-praticas-integrativas-ecomplementares-de-saude-pmpics-e-da-outras-providencias. Acesso em: 20 set. 2016.

UBERLÂNDIA (MG). Prefeitura Municipal. Lei municipal no 11.309 de 18 de fevereiro de 2013. Autoriza a criação do Programa Municipal de Práticas Integrativas e Complementares de Saúde PMPICS e dá outras providências. Uberlândia, MG: Prefeitura Municipal, 2013. Disponível em https://leismunicipais.com.br/a1/mg/u/uberlandia/lei-ordinaria/2013/1130/11309/lei-ordinaria-n-113092013-autoriza-a-criacao-do-programa-municipal-de-praticas-integrativas-e-complementares-de-saudepmpics-e-da-outras-providencias. Acesso em: 20 set. 2016.

UBERLÂNDIA (MG). Câmara Municipal. Veto total à proposição de lei no 997/12, que autoriza a criação do Programa Municipal de Práticas Integrativas Complementares de Saúde - PMPICS, e dá outras providências. Uberlândia, MG: Câmara Municipal, 2012. Disponível em: http://www.portalunisaude.com.br/arquivos/file/veto\%20prefeito.pdf. Acesso em: 25 jun. 2018. 